\title{
The Correlation between the Duration of Fetal Extraction during Cesarean Section and Development of Transient Tachypnea of the Newborn
}

\author{
MOHAMAD M.I. EL-BOKL, M.D.*; DOAA Sh. ABO ZAHER, M.D.*; \\ ABD EL-RAHMAN A. ABD EL-RAZEK, M.D.**; MONA M. SEDIEK KHALIL, M.D.* and \\ HEBA M. MARIE, M.D.* \\ The Departments of Obstetrics \& Gynecology* and Pediatrics**, Faculty of Medicine, Cairo University
}

\begin{abstract}
Background: Opted to assess the relation between each of the induction delivery time and the uterine incision delivery time during $\mathrm{CD}$ with the incidence of TTN.

Study Design: A prospective cohort study.

Patients and Methods: We included 100 pregnant women who were delivered by CS under spinal anesthesia, (completed 37 weeks), having singleton, non-anomalous fetus, at Kasr El-Aini Hospital, Cairo University, from May 2014 to December 2014. Two time intervals (in seconds) were recorded: A) The induction delivery interval (from the start of induction of anesthesia till cord clamping=I-C interval), B) The uterine incision delivery interval (from the time of uterine incision till cord clamping $=\mathrm{U}-\mathrm{C}$ interval). Neonatal parameters as regard; gender, weight, \& 5 minute Apgar score were reportedas well as the development of TTN.
\end{abstract}

Results: The reported I-C interval \& U-C interval ranged between 335-999sec (mean $\pm \mathrm{SD} ; 696 \pm 129.7) \& 23-66 \mathrm{sec}$ (mean \pm SD; $48.7 \pm 14.32$ ) respectively. The 5 minute Apgar score range was between 6 to 10 (median; 9) \& the neonatal respiratory rate range was from $39 / \mathrm{min}$ to $66 / \mathrm{min}$ (median; 44). The 5 minute Apgar score did not show any correlation, neither with the different variables of the study, nor with the I-C \& U-C intervals. Out of the 100 delivered neonates, 8 neonates $(8 \%)$ developed TTN \& were admitted to the NICU for further management. TTN development showed a significant correlation with the Gestational Age (GA), otherwise, there had been no statistical correlation between the development of TTN and the duration of fetal extraction during CS.

Conclusion: According to our finding TTN is not related to the length of the operative procedure till fetal delivery in cases under spinal anesthesia. We recommend the need of carrying on studies with larger populations, to offer the optimal time limit safe for fetal delivery and other possible risks for the development of TTN.

Key Words: Cesarean delivery - Spinal anesthesia - I-C interval - U-C interval - TTN.

Correspondence to: Dr. Doaa Sh. Abo Zaher, E-Mail: doaash@live.com

\section{Introduction}

IN current obstetric practice, Cesarean Delivery (CD) comprises the most frequent surgical procedure [1]. This situation has been reflected upon the development of neonatal respiratory disorders, especially the occurrence of Transient Tachypnea of the Newborn (TTN) [2] .

TTN; also known as-type 2 RDS, wet lung syndrome-represents the commonest cause of neonatal respiratory distress, with a prevalence range between 0.33 to $3.9 \%$. It is a pulmonary disorder that affects lung parenchyma and characterized by pulmonary edema $[2,3]$. Despite being a benign and self-limiting disease, still the associated hypoxemia with TTN and respiratory failure may increase the morbidity, length of hospital stay, risk of chronic pulmonary disease later on $\&$ death $[4,5]$

With the dramatically rising rates of $\mathrm{CD}$, there comes the urgent need to better understand the influence of the operative time on neonatal outcome [6]. Moreover, the time lagging from uterine incision to fetal delivery, though brief, yet challenging [7]. Many studies assessed the effect of induction delivery time on neonatal outcome under General Anesthesia (GA), but only few studies were investigated in cases under spinal anesthesia [8]. Sympathetic block created by spinal anesthesia will diminish the uteroplacental blood flow, and if the induction delivery time is prolonged, this may jeopardize the placental blood flow and affect the neonatal outcome [8]. On the other hand, no strict guidelines are set regarding the importance of uterine incision to delivery interval [1] .

Thus, in the current study, we opted to assess the relation between each of the induction delivery 
time and the uterine incision delivery time during $\mathrm{CD}$ with the incidence of TTN, as a reflection the neonatal respiratory outcome.

\section{Patients and Methods}

We conducted a prospective cohort study at Kasr El-Aini Hospital, Cairo University, over a period of 8 months, from May 2014 to December 2014, observing parturients scheduled for CD under spinal anesthesia. Approval of our local ethical committee has been received.

We included cases at term (completed 37 weeks), having singleton, non-anomalous fetus. Cases with maternal medical disorders, suspected intrauterine growth restriction, maternal drug intake prior to $\mathrm{CD}$, pre-mature rupture of membranes have been excluded. Cesarean deliveries due to obstetric emergency; such as, fetal distress, antepartum hemorrhage, have been also excluded.

All recruited cases have been subjected to detailed history taking, obstetric examination, and ultrasound imaging to confirm fitting in the inclusion criteria. The anesthesia and surgical techniques were standardized. Two time intervals (in seconds) were recorded: A- The induction delivery interval (from the start of induction of anesthesia till cord clamping=I-C interval), B- The uterine incision delivery interval (from the time of uterine incision till cord clamping=U-C interval). Neonatal gender, weight, and 5 minute Apgar score were reported. The diagnosis of TTN was established by the pediatric team based on the following criteria (3); Occurrence of tachypnea (defined as respiratory rate $>60 / \mathrm{min}$ ) within 6 hours from delivery, persistence of the condition for at least 12 hours, one of chest X-ray findings (prominent vascular markings, perihilar congestion, widening of interlobar fissure), and exclusion of known respiratory or non-respiratory disorder (as meconium aspiration syndrome, congenital heart disease, hypoglycemia, hypocalcemia, polycythemia).

Statistical method: The data were coded, entered and processed on an IBM-PC compatible computer using Statistical Package for Social Sciences (SPSS) Version 16. A $p$-value of $<0.05$ was considered significant.

Mann-Whitney Test, $t$-test and Chi-Square tests were used to assess the statistical significance of the difference between two population means and medians in a study involving independent samples.

\section{Results}

The current study included 100 pregnant women who were delivered by CS under spinal anesthesia, fulfilling the criteria formerly mentioned, at Kasr El-Aini Hospital, Cairo University, from May 2014 to December 2014.

Maternal and fetal characteristics are described in terms of range \& mean $\pm \mathrm{SD}$, and/or percentage in (Table 1).

Table (1): Maternal \& fetal characteristics.

\begin{tabular}{llll}
\hline & Range & Mean $( \pm \mathrm{SD})$ & $\begin{array}{c}\text { Number } \\
\text { percentage } \\
\mathrm{n}(\%)\end{array}$ \\
\hline Maternal age (years) & $19-34$ & $26.56( \pm 4.52)$ & \\
Gestational age (weeks) & $38-40$ & $38.83( \pm 0.85)$ & \\
Fetal presentation: & & & $77(77 \%)$ \\
Cephalic & & $19(19 \%)$ \\
Breech & & $4(4 \%)$ \\
Transverse & & $19(19 \%)$ \\
Cesarean delivery $(C D):$ & & $81(81 \%)$ \\
Primary CD & & 33 \\
Previous CD & & 45 \\
Previous 1 CS & & 1 \\
Previous 2 CS & & \\
Previous 3 CS & & \\
Previous 4 CS & & \\
- Neonatal birth & $2400-4100$ & $3217( \pm 331)$ & \\
weight (grams) & & & $48(48 \%)$ \\
Neonatal gender: & & & $52(52 \%)$ \\
$\quad$ Male & & \\
Female & & & \\
\hline
\end{tabular}

The reported I-C interval \& U-C interval ranged between 335-999sec (mean \pm SD; 696 \pm 129.7$) \&$ $23-66 s e c$ (mean $\pm \mathrm{SD} ; 48.7 \pm 14.32$ ) respectively. The 5 minute Apgar score range was between 6 to 10 (median; 9) \& the neonatal respiratory rate range was from $39 / \mathrm{min}$ to $66 / \mathrm{min}$ (median; 44).

The 5 minute Apgar score did not show any correlation, neither with the different variables of the study, nor with the I-C \& U-C intervals Fig. (1). The number of repeated cesarean deliveries did not seem to affect the 5 minute Apgar score from the statistical point of view, with a range (median); 7-10 (9) \& a $p$-value; 0.256.

Out of the 100 delivered neonates, 8 neonates (8\%) developed TTN and were admitted to the NICU for further management. TTN development showed a significant correlation with the Gestational Age (GA), otherwise, there had been no statistical correlation between the development of TTN \& any of the other studied factors mentioned in (Table 2). 


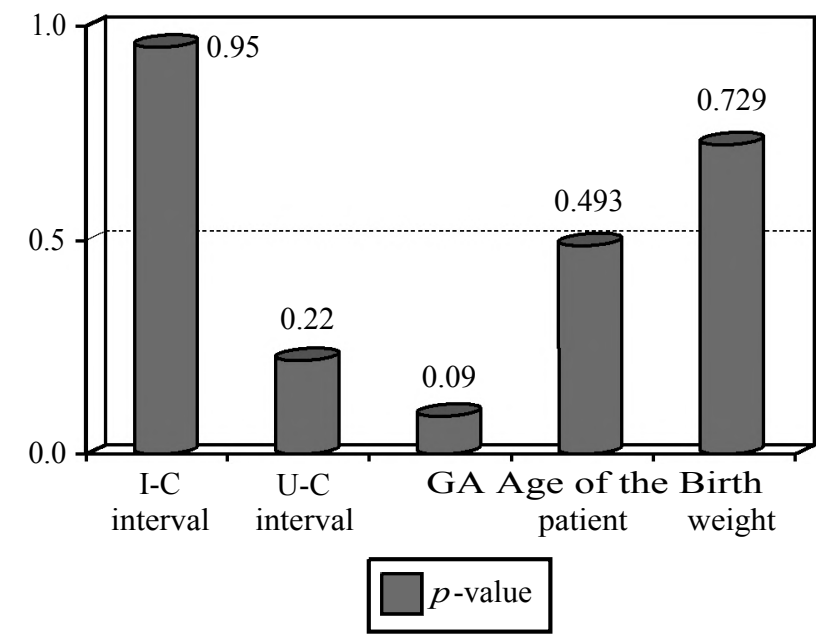

Fig. (1): The correlation between Apgar 5 min \& the different variables.

I-C interval : The duration from induction of anesthesia till cord

U-C interval : The duration form uterine incision till cord clamping. GA : Gestational age.

Table (2): Characteristics of neonates who developed TTN.

\begin{tabular}{|c|c|c|c|c|}
\hline Characteristic & $\begin{array}{r}\text { TTN } \\
(\mathrm{n}=8)\end{array}$ & $\begin{array}{c}\text { No TTN } \\
(\mathrm{n}=92)\end{array}$ & $\begin{array}{c}p- \\
\text { value }\end{array}$ & Significance \\
\hline I-C duration & $695 \pm 181$ & $656 \pm 123$ & 0.268 & NS \\
\hline U-C duration & $57 \pm 0.01$ & $48 \pm 14.6$ & 0.163 & NS \\
\hline Gestational age & $38.1 \pm 0.35$ & $39.01 \pm 0.73$ & $0.002 *$ & S \\
\hline $\begin{array}{l}\text { Neonatal gender: } \\
\text { Male }(\mathrm{n}=37) \\
\text { Female }(\mathrm{n}=63)\end{array}$ & $\begin{array}{l}2(5.4 \%) \\
6(9.5)\end{array}$ & $\begin{array}{l}35(94.6 \%) \\
57(90.5)\end{array}$ & 0.707 & NS \\
\hline Apgar score & $8(7-10)$ & $9(6-10)$ & 0.548 & NS \\
\hline
\end{tabular}

In data analysis of the secondary outcomes, a strong correlation has been found between the number of previous CS and duration of the I-C interval ( $p$-value; 0.01$)$, but none has been noted as regards the duration of the U-C interval ( $p$ value; 0.40 ). The I-C duration (in sec) was 607.5 $( \pm 125.2)$ and $683.4( \pm 127.2)$, whereas, the U-C duration (in sec) was $49.4( \pm 15.6)$ and 48.6 $( \pm 13.99)$, in cases of primary $C D$ and repeated CD respectively.

\section{Discussion}

TTN, being the most common cause of neonatal $\mathrm{RD}$, is closely related to $\mathrm{CD}$. This association is more pronounced when the cesarean is scheduled before initiation of labor [2,9]. On the other hand, spinal anesthesia has become the default anesthetic procedure offered in everyday obstetric practice, except when general anesthesia is necessary in certain indications. The time interval from induction of anesthesia till delivery has been stated by some investigators to be a relevant parameter for the development of TTN $[\mathbf{9 , 1 0 ]}$.

In our prospective study, we documented the I-D, \& U-D intervals in relation to the occurrence of TTN, together with other parameters as; GA, neonatal weight $\&$ gender, \& 5 th minute Apgar score. Over the 100 parturients who delivered under spinal anesthesia, 8 cases developed TTN. The only significant correlation with TTN development was the GA, otherwise, no significant correlation was observed neither with the operative time, nor with the other studied factors.

The significant correlation between the development of TTN \& GA, provided by our results, has been mentioned by several investigators, who established as well an inverse relation between TTN \& GA [11].

As regards the fetal delivery time following the induction of anesthesia and uterine incision, to date, there are no clear guidelines for the optimal range \& how this may affect the neonatal respiratory outcome $[8]$. Our data are consistent with previous studies that did not find any significant association between the length of the operative time till delivery and neonatal respiratory outcomes $[7,12,13]$. But these studies had several limitations. The study conducted by Andersen et al., [12], included small sample size and focused on those who received general anesthesia. Though Maayan Metzger et al., [13] conducted a large study, they selected only the elective cesareans, which in turn may bias the results. On the contrary, Spain et al., [7], studied only the in labor cesareans and this may have two drawbacks. The first, being in labor, that may provide a protective effect upon the fetus, being subjected to the changes that occur in labor and may support the neonatal respiration after delivery. The second issue, is that being in labor, this may influence the surgeon for more expeditious action and will unavoidably affect the operative time till fetal delivery. These data support the idea of having a large safety margin for fetal delivery without neonatal respiratory morbidity and go pro safe fetal delivery, rather than a hasty one, as a priority $[\mathbf{7 , 1 2 , 1 3 ]}$.

Still, other researchers had a different point of view. Palan et al., stated that prolonged induction delivery time ( $>20 \mathrm{~min}$ ) in cases under spinal anesthesia was associated with low Apgar scores. Thus, concluded that spinal anesthesia may not be totally without harm, in terms of neonatal outcome, so long the time factor was ignored [8]. Gunaydin et al., suggested that reducing the time elapse from 
induction of spinal anesthesia till fetal delivery may be an important measure to decrease the incidence of TTN [10].

Neonatal male gender has been stated as one of the risk factors for the development of TTN [11], but our results did not find any gender difference of statistical significance in relation to the occurrence of TTN. This may be attributed to our small sample size.

In analysis of the secondary outcomes, low Apgar scores were neither related to the I-C and U-C intervals nor to TTN development. This comes in agreement with studies which stated that Apgar score was not affected by the length of the operative procedure $[\mathbf{1 , 1 3}]$. Still, it has been mentioned by other investigators that low Apgar scores were considered as a risk factor for the development of TTN [14]. Our results highlighted that I-C and U$\mathrm{C}$ intervals were prolonged in linear correlation with the increase in number of previous CS. This can be explained by the increased adhesions and surgical difficulties that may be encountered with the increase in number of previous CS. This point of view has been approved by many researchers $[6,15]$.

We believe that the strength of our study lies in being of prospective nature and the standardization of the anesthesia technique provided to all cases. Yet, the small sample size represents a considerable limitation to our study.

In conclusion, we assume that TTN is not related to the length of the operative procedure till fetal delivery in cases under spinal anesthesia. We recommend the need of carrying on studies with larger populations, to offer the optimal time limit safe for fetal delivery and other possible risks for the development of TTN.

\section{References}

1- ROSSOUW J.N., HALL D. and HARVEY J.: Time between skin incision and delivery during cesarean. I.J.O.G., 121: 82-5, 2013.

2- OMAYGENC D.O., DOGU T., OMAYGENC M.O., OZMEN F., ALBAYRAK M.D., GULER G.B., GUR E.K. and OZENC E.: Type of anesthesia affects neonatal wellbeing and frequency of transient tachypnea in elective cesarean sections. J. Matern. Fetal. Neonatal. Med., 28 (5): 568-72, 2015.
3- KASAP B., DUMAN N., OZER E., TATLI M., KUMRAL A. and ÖZKAN H.: Transient tachypnea of the newborn predictive factor for prolonged tachypneas. Ped. Int., 50 (1): 81-4, 2008.

4- CHRISTIAN L.H. and KEVIN N.L.: Respiratory distress in the newborn. Am. Fam. Physician., 76: 987-94, 2007.

5- RAMACHANDRAPPA A. and JAIN L.: Elective cesarean section: It's impact on neonatal respiratory outcome. Clin. Perinatol., 35 (2): 373-vii, 2008.

6- BUSCH J.M. and MORRISON J.C.: Factors affecting caesarean operative time and the effect of operative time on pregnancy outcomes. Aust. N.Z.J. Obstet. Gynaecol., 48 (3): 286-91, 2008.

7- SPAIN J.E., TUULI M., STOUT M.J., ROEHL K.A., ODIBO A.O., MACONES G.A. and CAHILL A.G.: Time from uterine incision to delivery and hypoxic neonatal outcome. Am. J. Perinatol., 32: 497-502, 2015.

8- PALAN A. and AGRAWAL N.K.: Effect of induction delivery time on Apgar score in lower segment cesarean section under spinal anesthesia. People's Journal of Scientific Research, 9 (1): 20-3, 2016.

9- KELEŞ E., YAZGAN H., GEBEŞÇE A. and PAKR E.: The type of anesthesia used during cesarean section is related to the transient tachypnea of the newborn. I.S.R.N. Pediatrics, 2013.

10- GUNAYDIN B., TAS A., AKSAKAL N., FAYDAC1 F. and MURAT HiRFANOGLU I.: Retrospective analysis on transient tachypnea of the newborn: Is it associated with spinal anesthesia after cesarean section? Gaziantep. Med. J.; 18 (2): 77-80, 2012.

11-HANSEN A.K., WISBORG K., ULDBJERG N. and HENRIKSEN T.B.: Elective caesarean section and respiratory morbidity in the term and near-term neonate. Acta Obstet. Gynecol. Scand, 86 (4): 389-94, 2007.

12-ANDERSEN H.F., AUSTER G.H., MARX G.F. and MERKATZ I.R.: Neonatal status in relation to incision intervals, obstetric factors, and anesthesia at cesarean delivery. Am. J. Perinatol., 4 (4): 279-83, 1987.

13- MAAYAN-METZGER A., SCHUSHAN-EISEN I., TODRIS L., ETCHIN A. and KUINT J.: The effect of time intervals on neonatal outcome in elective cesarean delivery at term under regional anesthesia. Int. J. Gynaecol. Obstet., 111 (3): 224-8, 2010.

14- GROSS T.L., SOKOL R.J., KWONG M.S., WILSON M and KUHNERT P.M.: Transient tachypnea of the newborn: The relationship to preterm delivery and significant neonatal morbidity. Am. J. Obstet. Gynecol., 146 (3): 236-41, 1983

15- WILSON S.H., FECHO K., MARSHALL J. and SPIELMAN F.: Factors influencing cesarean delivery operative times: A prospective observational cohort study. Int. J. Obstet. Anesth., 19 (4): 417-21, 2010. 


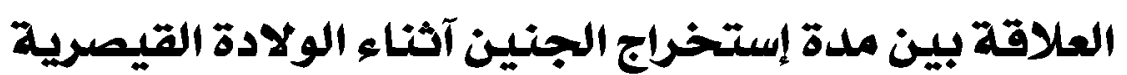

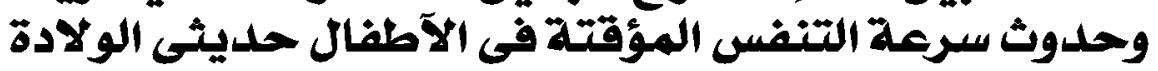

الهدف: دراسة تآثير كلا من المدة من بدء التخدير حتى إستخراج الجنين والمدة من فتح الرحم حتى إستخراج الجنين آثثاء الولادة القيصرية على حلوث التنفس المؤقت لدى حديثى الوناة عن بلادة.

$$
\text { تصميم الدراسة: دراسة مستقبلية. }
$$

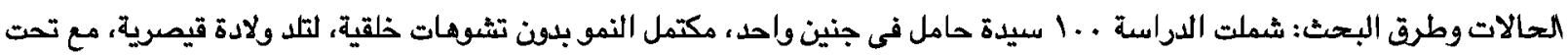

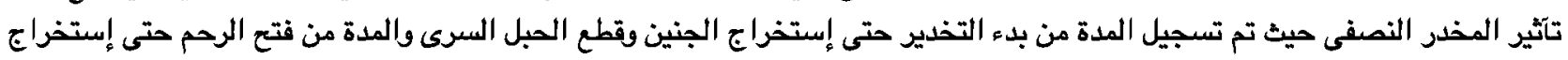

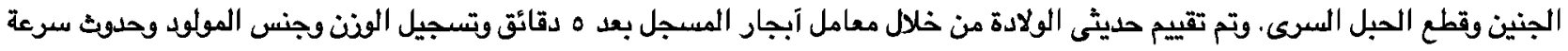

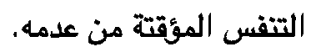

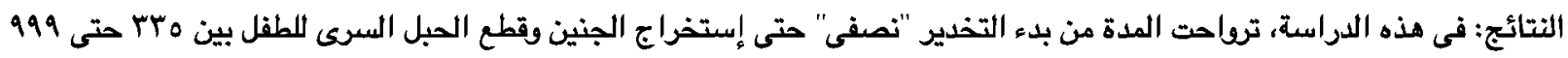

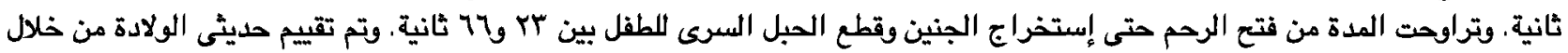

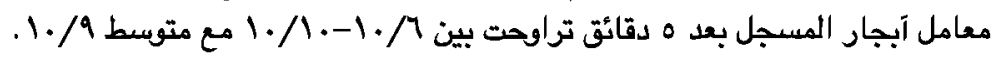

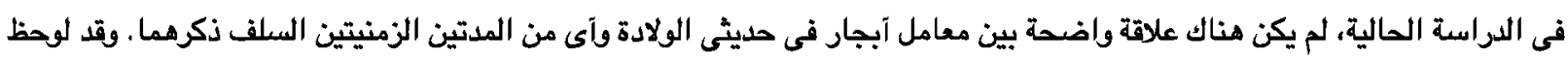

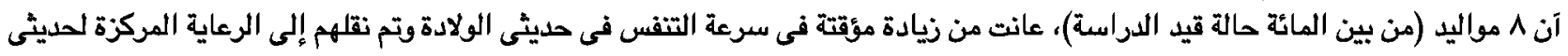

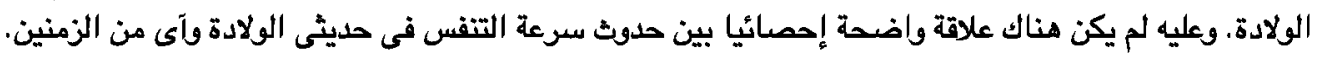

الإستتاج: طبقا لهذه الدراسة لا يوجد علاقة واضحة إحصائيا بين مدة إستخراج الجنين آثناء الولادة القيصرية وحدوث سرعة التنفس

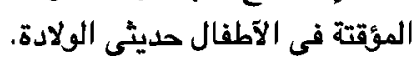

